\title{
Two-Sided Group Chain Sampling Plans Based on Truncated Life Test for Generalized Exponential Distribution
}

\author{
Nazrina Aziz ${ }^{1,2, *}$ Zahirah Hasim ${ }^{1}$, Zakiyah Zain ${ }^{1,2}$ \\ ${ }^{1}$ Department of Mathematics \& Statistics, School of Quantitative Sciences, Universiti Utara Malaysia, 06010 UUM Sintok, Kedah, \\ Malaysia \\ ${ }^{2}$ Institute of Strategic Industrial Decision Modelling (ISIDM), Universiti Utara Malaysia, 06010 UUM Sintok, Kedah, Malaysia
}

Received November 18, 2020; Revised May 25, 2021; Accepted June 4, 2021

\section{Cite This Paper in the following Citation Styles}

(a): [1] Nazrina Aziz, Zahirah Hasim, Zakiyah Zain, "Two-Sided Group Chain Sampling Plans Based on Truncated Life Test for Generalized Exponential Distribution," Mathematics and Statistics, Vol. 9, No. 4, pp. 439 - 444, 2021. DOI: 10.13189/ms.2021.090404.

(b): Nazrina Aziz, Zahirah Hasim, Zakiyah Zain (2021). Two-Sided Group Chain Sampling Plans Based on Truncated Life Test for Generalized Exponential Distribution. Mathematics and Statistics, 9(4), 439 - $444 . \quad$ DOI: 10.13189/ms.2021.090404.

Copyright $\mathrm{C} 2021$ by authors, all rights reserved. Authors agree that this article remains permanently open access under the terms of the Creative Commons Attribution License 4.0 International License

\begin{abstract}
Acceptance sampling is an important technique in quality assurance; its main goal is to achieve the most accurate decision in accepting lot using minimum resources. In practice, this often translates into minimizing the required sample sizes for the inspection, while satisfying the maximum allowable risks by consumer and producer. Numerous sampling plans have been developed over the past decades, the most recent being the incorporation of grouping to enable simultaneous inspection in the two-sided chain sampling which considers information from preceding and succeeding samples. This combination offers improved decision accuracy with reduced inspection resources. To-date, two-sided group chain sampling plan (TSGCh) for characteristic based on truncated lifetime has only been explored for Pareto distribution of the $2^{\text {nd }}$ kind. This article introduces TSGCh sampling plan for products with lifetime that follows generalized exponential distribution. It focuses on minimizing consumer's risk and operates with three acceptance criteria. The equations that derived from the set conditions involving generalized exponential and binomial distributions are mathematically solved to develop this sampling plan. Its performance is measured on the probability of lot acceptance and number of minimum groups. A comparison with the established new two-sided group chain (NTSGCh) indicates that the proposed TSGCh
\end{abstract}

sampling plan performs better in terms of sample size requirement and consumers' protection. Thus, this new acceptance sampling plan can reduce the inspection time, resources, and costs via smaller sample size (number of groups), while providing the desired consumers' protection.

Keywords Exponential Distribution, Group Chain Sampling, Probability of Lot Acceptance, Consumer's Risk, Number of Minimum Groups

\section{Introduction}

Acceptance sampling is a statistical technique used in a process of making decision or judgement to either reject or accept a lot based on information acquired from its sample. Such inference using a sample of a certain proportion from the population instead of inspecting the entire lot is preferable due to its saving of time, resources, and costs. Also, the risk of accidental damaging of products due to mishandling during inspection is greatly reduced. Nevertheless, as with any statistical inference there exist the risks of accepting a bad lot (type II error) and rejecting a good lot (type I error) [1]. The detailed 
procedure of the inspection which aims to minimize these inevitable risks is known as acceptance sampling plan.

Sampling plans are often categorized into two types which are attribute and variable. Attribute sampling plan considers "go, no-go" or "pass or fail" as a basis of measurement, while variable involves the quantitative measurement of a continuous variable. Numerous attribute sampling plans have been established, for instance, chain sampling plan (ChSP-1), single sampling plan (SSP), new two-sided complete group chain (NTSCGChSP), new two-sided group chain sampling plan (NTSGChSP), and group chain sampling plan (GChSP), which are described next.

SSP is the first plan in the attribute sampling plan as introduced by Epstein in 1954 [2]. It was initially developed to allow for 0 or 1 defective in the current lot as acceptance criteria. Due to its rapid drop in the probability of lot acceptance even with a small increase of fraction defective, SSP is not suitable for handling high-quality products. To fix the issue, Dodge proposed a ChSP-1 in 1955 [3], which includes information from the preceding lot. The currently inspected lot is accepted when no defective in found in its sample, or when one defective occurred in the current sample and none from the preceding sample. Tactfully utilizing the readily available information from the preceding lot, ChSP-1 saves inspection time, resources and costs, while achieving relatively higher probability of acceptance compared to SSP. When lifetime of product is inspected within prespecified time often known as truncated time, various distributions have been applied in ChSP-1 such as Weibull [4], generalized Rayleigh [5] and inverse Rayleigh [6].

Meanwhile, group chain sampling plan (GChSP) [7] originated from the idea ofcombiningtheChSP-1[3] and group sampling plan (GSP) [8, 9]. Having adopted the procedure of ChSP-1 and inspected the sample in groups simultaneously, GChSP further reduces the time consumed for the producer and saves costs [10]. The GChSP has been investigated by many researchers using different distributions; examples include the Pareto of the 2nd Kind [7], log-logistic [11], Rayleigh [12], inverse Rayleigh [13], exponential [14] and gamma [15] distributions. Later, the very concept of chain from GChSP has been extended to incorporate the succeeding lot information as well, and this is known as two-sided. In 2015, anew two-sided complete group chain sampling plan (NTSCGCh) was initiated by Mughal, Zain and Aziz [16]. It was extended from the earlier modified group chain sampling plan (MGChSP) and group chain sampling plan (GChSP). The improvement on this plan is the combination of the succeeding and preceding in lot information and only accepting the lot if one of the preceding or succeeding have zero defective. Consequently, the plan offers a relatively higher probability of lot acceptance and smaller sample size requirement.

More recently, Farouk, Aziz and Zain [17] altered the acceptance criteria influencing the probability of lot acceptance and proposed a new two-sided group chain sampling plan using log-logistic distribution. The plan uses four acceptance criteria compared tot he existing plans of NTSCGCh SP which operates with five acceptance criteria and two-sided group chain sampling (TSGChSP) which uses only three acceptance criteria. It was reported that NTSGChSP has better performance than NTSCGChSP.To the best of our knowledge, the performance of TSGChSP has not been identified and to-date, the TSGChSP has only been developed for product lifetime that follows Pareto of the 2nd Kind distribution [16]. In order to cater for wider potential applications, this study proposes a TSGChSP with three acceptance criteria and is based on generalized exponential distribution. The performance of TSGChSP will be compared with NTGChSP in the condition of the probability of lot acceptance and the number of minimum groups.

\section{Methodology}

The generalized exponential distribution (GE) is important in reliability studies as product lifetime data are often distributed in this manner. Its characteristics with the unique property of 'lack of memory' [14] renders GE widely applicable in electrical and electronics industries. Its cumulative distribution function (CDF) at time $t$ is specified by:

$$
F(t ; \sigma)=\left[1-\exp \left(-\frac{t}{\sigma}\right)\right]^{\lambda}, t>0,
$$

where the shape parameter is $\lambda$ and scale parameter is $\sigma$. The probability of failure, $p$ can be reported as

$$
p=\left[1-\exp \left(\frac{-a \mu_{0}}{\mu}\right)\right]^{\lambda},
$$

where $a$ is the specific constant given by the ratio of the test termination time, $t_{0}$ to the specified mean life, $\mu_{0}$, while $\mu$ is the true mean life of the product. This methodology section further describes the probability of lot acceptance as a function of the probability of failure or fraction defective, $p$ in developing the proposed acceptance sampling plan.

In the beginning of the typical operating procedure for acceptance sampling, a sample of size $n$ was selected randomly from a lot of size $N$, and the number of defectives, $d$ was counted. The acceptance and rejection conditions in the procedure are:

1. The current lot is also accepted when $E=1$.

2. The current lot is accepted when the total number of defectives, $E=0$.

3. The current lot is rejected when $E>1$.

Based on these acceptance criteria, the probability of lot 
acceptance, $L(p)$ when $i=j$, becomes:

$$
L(p)=P_{0}^{2 i}\left[P_{0}+2 i P_{1}\right]
$$

where $P_{1}$ is the probability of one defective and $P_{0}$ is the probability of zero defective in the sample. Since the inspection is based on pass-fail outcome of independent trials, a binomial distribution is employed in deriving the $P_{0}$ and $P_{l}$ using Equation (3). Then, the number of minimum groups, $g$ in TSGChSP can be attained when the specific condition is satisfied:

$$
L(p) \leq \beta .
$$

Thus, the probability of lot acceptance can then be expressed as:

$$
L(p)=(1-p)^{g r(2 i+1)}\left[1+\frac{2 i g r p}{1-p}\right] .
$$

The four key design parameters in the present study are the specified constant, consumer's risk, the number of products, and the number of preceding lots and succeeding lots. Table 1 shows the set values of these parameters respectively, as published by previous researchers [18].

Table 1. Design parameter values

\begin{tabular}{ccccccccc}
\hline$a$ & 0.25 & 0.50 & 0.75 & 1.00 & 1.25 & 1.50 & 1.75 & 2.00 \\
$\beta$ & 0.01 & 0.05 & 0.10 & 0.25 & & & & \\
$i$ & 1 & 2 & 3 & 4 & & & & \\
$r$ & 2 & 3 & 4 & 5 & & & & \\
\hline
\end{tabular}

\section{Results and Discussion}

The following results are obtained from the earlier mathematical formulation using MS Excel. Table 2 shows the minimum number of groups, $g$ for the TSGChSP using generalized exponential distribution based on specific values, $a$ and shape parameter, $\lambda=1$. Meawhile, Table 3 displays the probability of lot acceptance with shape parameter, $\lambda=1$.

Reading horizontally on the first row of the results, the number of minimum groups, $g$ decreases when the number of specific constant, $a$, is raised with the allowable number of preceding, $i=1$, and number of products, $r=2$. This means that if the test time is relatively longer as compared to the specified mean life of the product, then a smaller sample size $(n=r g)$ is needed. Also, $g$ decreases as the consumer's risk, $\beta$, number of preceding lots, $i$, and the number of products, $r$, are increased. This trend can be viewed vertically down the fourth column where $a=0.25$. In essence, a smaller number of minimum groups can be achieved if more information (result) is gathered from more preceding samples, or more products are considered in each group, or consumer is willing to compromise the risk of accepting bad lots. It is to be noted that in practice, these aspects can be designed for the right balance of combination as desired by the consumers with mutual

\begin{tabular}{|c|c|c|c|c|c|c|c|c|c|c|}
\hline \multirow[b]{2}{*}{$\beta$} & \multirow[b]{2}{*}{$i$} & \multirow[b]{2}{*}{$r$} & \multicolumn{8}{|c|}{$a$} \\
\hline & & & 0.25 & 0.50 & 0.75 & 1.00 & 1.25 & 1.50 & 1.75 & 2.00 \\
\hline \multirow{4}{*}{0.01} & 1 & 2 & 5 & 3 & 2 & 2 & 1 & 1 & 1 & 1 \\
\hline & 2 & 3 & 2 & 1 & 1 & 1 & 1 & 1 & 1 & 1 \\
\hline & 3 & 4 & 1 & 1 & 1 & 1 & 1 & 1 & 1 & 1 \\
\hline & 4 & 5 & 1 & 1 & 1 & 1 & 1 & 1 & 1 & 1 \\
\hline \multirow{4}{*}{0.05} & 1 & 2 & 3 & 2 & 2 & 1 & 1 & 1 & 1 & 1 \\
\hline & 2 & 3 & 2 & 1 & 1 & 1 & 1 & 1 & 1 & 1 \\
\hline & 3 & 4 & 1 & 1 & 1 & 1 & 1 & 1 & 1 & 1 \\
\hline & 4 & 5 & 1 & 1 & 1 & 1 & 1 & 1 & 1 & 1 \\
\hline \multirow{4}{*}{0.10} & 1 & 2 & 3 & 2 & 1 & 1 & 1 & 1 & 1 & 1 \\
\hline & 2 & 3 & 2 & 1 & 1 & 1 & 1 & 1 & 1 & 1 \\
\hline & 3 & 4 & 1 & 1 & 1 & 1 & 1 & 1 & 1 & 1 \\
\hline & 4 & 5 & 1 & 1 & 1 & 1 & 1 & 1 & 1 & 1 \\
\hline
\end{tabular}
agreement by the producers.

Table 2. Number of minimum groups for generalized exponential distribution when $\lambda=1$ 
Table 3. Probability of lot acceptance for generalized exponential distribution when $\lambda=1$

\begin{tabular}{|c|c|c|c|c|c|c|c|c|c|}
\hline \multirow[b]{3}{*}{$\beta$} & \multirow[b]{3}{*}{$g$} & \multirow[b]{3}{*}{$a$} & \multicolumn{7}{|c|}{$\underline{\mu}$} \\
\hline & & & & & & $\mu_{0}$ & & & \\
\hline & & & 1 & 2 & 4 & 6 & 8 & 10 & 12 \\
\hline \multirow{8}{*}{0.01} & 5 & 0.25 & 0.0037 & 0.0861 & 0.3512 & 0.5303 & 0.6402 & 0.7115 & 0.7606 \\
\hline & 3 & 0.50 & 0.0011 & 0.0490 & 0.2738 & 0.4558 & 0.5759 & 0.6567 & 0.7135 \\
\hline & 2 & 0.75 & 0.0012 & 0.0515 & 0.2793 & 0.4608 & 0.5799 & 0.6599 & 0.7161 \\
\hline & 2 & 1.00 & 0.0001 & 0.0153 & 0.1629 & 0.3317 & 0.4608 & 0.5546 & 0.6236 \\
\hline & 1 & 1.25 & 0.0061 & 0.1052 & 0.3784 & 0.5519 & 0.6565 & 0.7239 & 0.7703 \\
\hline & 1 & 1.50 & 0.0018 & 0.0607 & 0.2972 & 0.4766 & 0.5925 & 0.6698 & 0.7239 \\
\hline & 1 & 1.75 & 0.0006 & 0.0346 & 0.2315 & 0.4092 & 0.5324 & 0.6176 & 0.6787 \\
\hline & 1 & 2.00 & 0.0002 & 0.0195 & 0.1790 & 0.3495 & 0.4766 & 0.5679 & 0.6348 \\
\hline \multirow{8}{*}{0.05} & 3 & 0.25 & 0.0490 & 0.2738 & 0.5759 & 0.7135 & 0.7868 & 0.8313 & 0.8609 \\
\hline & 2 & 0.50 & 0.0153 & 0.1629 & 0.4608 & 0.6236 & 0.7161 & 0.7739 & 0.8130 \\
\hline & 2 & 0.75 & 0.0012 & 0.0515 & 0.2793 & 0.4608 & 0.5799 & 0.6599 & 0.7161 \\
\hline & 1 & 1.00 & 0.0195 & 0.1790 & 0.4766 & 0.6348 & 0.7239 & 0.7797 & 0.8174 \\
\hline & 1 & 1.25 & 0.0061 & 0.1052 & 0.3784 & 0.5519 & 0.6565 & 0.7239 & 0.7703 \\
\hline & 1 & 1.50 & 0.0018 & 0.0607 & 0.2972 & 0.4766 & 0.5925 & 0.6698 & 0.7239 \\
\hline & 1 & 1.75 & 0.0006 & 0.0346 & 0.2315 & 0.4092 & 0.5324 & 0.6176 & 0.6787 \\
\hline & 1 & 2.00 & 0.0002 & 0.0195 & 0.1790 & 0.3495 & 0.4766 & 0.5679 & 0.6348 \\
\hline \multirow{8}{*}{0.10} & 3 & 0.25 & 0.0490 & 0.2738 & 0.5759 & 0.7135 & 0.7868 & 0.8313 & 0.8609 \\
\hline & 2 & 0.50 & 0.0153 & 0.1629 & 0.4608 & 0.6236 & 0.7161 & 0.7739 & 0.8130 \\
\hline & 1 & 0.75 & 0.0607 & 0.2972 & 0.5925 & 0.7239 & 0.7938 & 0.8363 & 0.8646 \\
\hline & 1 & 1.00 & 0.0195 & 0.1790 & 0.4766 & 0.6348 & 0.7239 & 0.7797 & 0.8174 \\
\hline & 1 & 1.25 & 0.0061 & 0.1052 & 0.3784 & 0.5519 & 0.6565 & 0.7239 & 0.7703 \\
\hline & 1 & 1.5 & 0.0018 & 0.0607 & 0.2972 & 0.4766 & 0.5925 & 0.6698 & 0.7239 \\
\hline & 1 & 1.75 & 0.0006 & 0.0346 & 0.2315 & 0.4092 & 0.5324 & 0.6176 & 0.6787 \\
\hline & 1 & 2.00 & 0.0002 & 0.0195 & 0.1790 & 0.3495 & 0.4766 & 0.5679 & 0.6348 \\
\hline
\end{tabular}

Table 4. Comparison of number of minimum groups when $\lambda=1,2,3$

\begin{tabular}{|c|c|c|c|c|c|c|c|c|c|}
\hline \multirow[b]{2}{*}{$\beta$} & \multirow[b]{2}{*}{$i$} & \multirow[b]{2}{*}{$r$} & \multirow[b]{2}{*}{$a$} & \multicolumn{2}{|c|}{$\lambda=1$} & \multicolumn{2}{|c|}{$\lambda=2$} & \multicolumn{2}{|c|}{$\lambda=3$} \\
\hline & & & & TSGCh & NTSGCh & TSGCh & NTSGCh & TSGCh & NTSGCh \\
\hline \multirow{8}{*}{0.01} & \multirow{8}{*}{1} & \multirow{8}{*}{2} & 0.25 & 5 & 5 & 3 & 23 & 2 & 102 \\
\hline & & & 0.50 & 3 & 3 & 2 & 7 & 1 & 18 \\
\hline & & & 0.75 & 2 & 2 & 1 & 4 & 1 & 8 \\
\hline & & & 1.00 & 2 & 2 & 1 & 3 & 1 & 4 \\
\hline & & & 1.25 & 1 & 1 & 1 & 2 & 1 & 3 \\
\hline & & & 1.50 & 1 & 1 & 1 & 2 & 1 & 2 \\
\hline & & & 1.75 & 1 & 1 & 1 & 2 & 1 & 2 \\
\hline & & & 2.00 & 1 & 1 & 1 & 1 & 1 & 2 \\
\hline
\end{tabular}

As anticipated, the probability of lot acceptance raises with the mean ratio that indicates the product quality. For instance, looking at the first row at $\beta=0.01, g=5, a=$ 0.25 , when the mean ratio increases from 1 to 12 , the probability of lot acceptance also increases from 0.0037 to 0.7606 , respectively. This means that when the product is of its best quality. In this case the actual product lifetime is 12 times its average lifetime, the chances of accepting the lot using this sampling plan increases to $76 \%$, compared to only $0.37 \%$ if the actual lifetime is equivalent to the average lifetime. The same increasing trend is evident when reading across horizontally on any rows in Table 3.

Table 4 and Table 5 outline the results for TSGCh and NTSGCh based on the number of minimum groups and the lot acceptance probability, respectively.

Upon inspection of Table 4, there is no difference in the number of minimum groups between TSGCh and NTSGCh when $\lambda=1$, suggesting that both plans consume 
the same amount of resources. However, when $\lambda=2,3$, TSGCh provides a smaller number of groups in comparison to the established NTSGCh. For example, in the first row when $\lambda=2$ and the design parameter $(\beta, i, r, a)$ is $(0.01,1,2,0.25)$, the producer only needs 3 groups when implementing TSGCh plan, while it will need 23 groups if NTSGCh is chosen. The smaller the number of groups, the shorter the inspection time which translates into lower costs.

Table 5 represents a comparison of the probability of lot acceptance when the design parameter $(\beta, i, r, a)=(0.01$, $1,2,0.25)$. Initially at $\lambda=1$, it is observed that TSGCh gives a smaller number (0.0037) compared to NTSGCh (0.0053). It is to be recalled that this sampling plan is designed to minimize consumer's risk, $\beta$ which is given by the probability of lot acceptance such that Equation (4) is satisfied. Thus, a lower probability of lot accepted is desired. As evident across the table horizontally, TSGCh consistently provides a lower probability compared to NTSGCh. This finding suggests that the former performs better than the latter in providing protection to consumers. For a clear visual comparison, Figure 1 portrays a graphical illustration.

Figure 1 shows the obvious separation of lines between the two OC curves of the plans and the gap widens with the mean ratio. For all the values of mean ratio (except 1), the TSGCh line remains below the NTSGCh line. This strongly suggests that the proposed sampling plan offers better protection to consumers since there is less chance of accepting a bad lot compared to the existing plan.

Table 5. Comparison of probability of lot acceptance when $\lambda=1,2,3$

\begin{tabular}{|c|c|c|c|c|c|c|c|c|c|c|}
\hline \multirow[b]{2}{*}{$\beta$} & \multirow[b]{2}{*}{$i$} & \multirow[b]{2}{*}{$r$} & \multirow[b]{2}{*}{$a$} & \multirow[b]{2}{*}{$\begin{array}{l}\text { Mean } \\
\text { Ratio } \\
\end{array}$} & \multicolumn{2}{|c|}{$\lambda=1$} & \multicolumn{2}{|c|}{$\lambda=2$} & \multicolumn{2}{|c|}{$\lambda=3$} \\
\hline & & & & & TSGCh & NTSGCh & TSGCh & NTSGCh & TSGCh & NTSGCh \\
\hline \multirow{7}{*}{0.01} & \multirow{7}{*}{1} & \multirow{7}{*}{2} & \multirow{7}{*}{0.25} & 1 & 0.0037 & 0.0053 & 0.00108 & 0.0080 & 0.00123 & 0.0099 \\
\hline & & & & 2 & 0.0862 & 0.1175 & 0.04897 & 0.4304 & 0.05154 & 0.7384 \\
\hline & & & & 4 & 0.3512 & 0.4501 & 0.27380 & 0.9081 & 0.27929 & 0.9915 \\
\hline & & & & 6 & 0.5303 & 0.6522 & 0.45582 & 0.9774 & 0.46081 & 0.9992 \\
\hline & & & & 8 & 0.6402 & 0.7645 & 0.57591 & 0.9922 & 0.57992 & 0.9998 \\
\hline & & & & 10 & 0.7115 & 0.8311 & 0.65671 & 0.9967 & 0.65989 & 1.0000 \\
\hline & & & & 12 & 0.7606 & 0.8733 & 0.71354 & 0.9984 & 0.71609 & 1.0000 \\
\hline
\end{tabular}

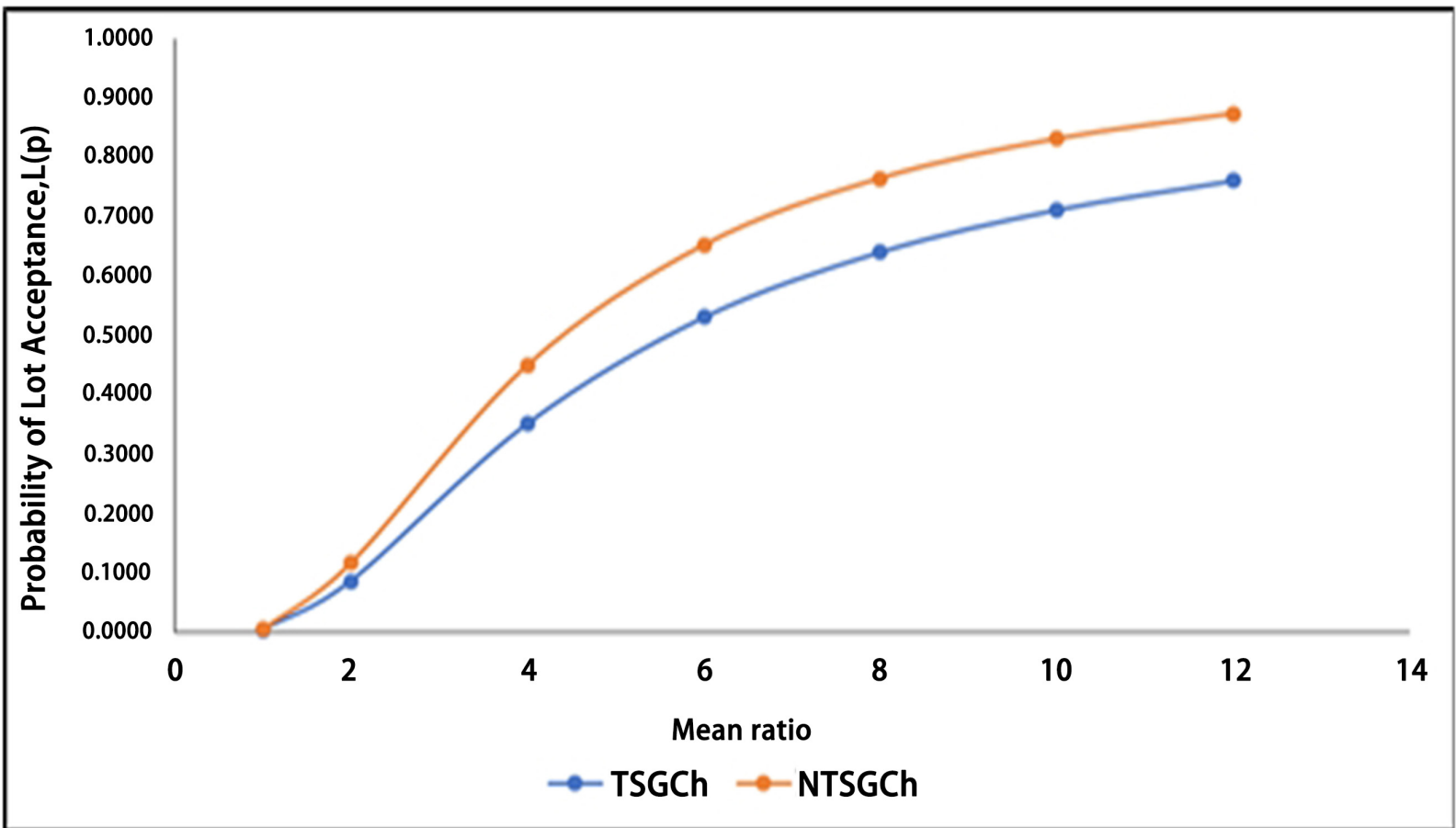

Figure 1. OC curve of TSGChSP and NTSGChSP based on GE distribution when $\lambda=1$ 


\section{Conclusions}

The TSGCh sampling plan based on the generalized exponential distribution is successfully developed with the focus on minimizing the consumer's risk. The results indicate that TSGCh sampling plan is superior to the existing NTSGCh sampling plan, both in terms of the probability of lot acceptance and number of minimum groups. A key implication is that this new acceptance sampling plan is able to reduce the inspection time via smaller sample size (number of groups) which consequently leads to reduced resources and costs. At the same time, it also provides greater protection for consumers through minimization of chances to accept bad lots which will disrupt manufacturing process and product yield. Another advantage is that this sampling plan can be customized to satisfy specific needs of the organization. Hence, this sampling plan is a worthwhile contribution to the field for both academics and practitioners.

\section{Acknowledgements}

The authors would like to express utmost gratitude and appreciation to Universiti Utara Malaysia and Ministry of Higher Education of Malaysia for the financial support (SCOE grant S/O: 13729).

\section{REFERENCES}

[1] Montgomery, D.C.Introduction to Statistical Quality Control.John Wiley \& Sons.2009.

[2] Epstein, B. Truncated life tests in the exponential case. The Annals of Mathematical Statistics, Volume 25, Issue 3, PP: 555-564.1954.

[3] Dodge, H. F. Chain sampling inspection plan. Industry Quality Control, Volume 11, Issue 4, PP: 10-13.1955.

[4] Ramaswamy, A.R.S.and Jayasri, S.Time Truncated Chain Sampling Plan for Weibull Distributions.International Journal of Engineering Research and General Scienc,e Volume 3, Issue 2. 2015.

[5] Ramaswamy, A.R.S. and Jayasri, S.Time Truncated Chain Sampling Plans for Generalized Rayleigh Distributions.International Referred Journal of Engineering and Science, Volume 3, Issue 2, PP: 49-53. 2014.

[6] Ramaswamy, A.R.S. and Jayasri, S.Time Truncated Chain Sampling Plans for Inverse Rayleigh Distributions.International Journal of Engineering and Inventions, Volume 3, Issue 6, PP: 41- 45. 2014.
[7] Mughal, A.R., Zain, Z.and Aziz, N. Time Truncated Group Chain Sampling Strategy for Pareto Distribution of the 2nd Kind.Research Journal of Applied Sciences, Engineering and Technology, Volume 10, Issue 4, PP: 471-474. 2015.

[8] Aslam, M., \& Jun, C. H. A group acceptance sampling plan for truncated life tests based on the inverse rayleigh distribution and log-logistic distributions. Pakistan Journal of Statistics, Volume 25, Issue 2, PP: 107-119.2009.

[9] Aslam, M., Jun, C. H., Lio, Y. L., \& Ahmad, M. Group acceptance sampling plans for the generalized Rayleigh distribution. International Journal of Intelligent Technologies and Applied Statistics, Volume 4, Issue 3, PP: 355-365.2011.

[10] Mughal, A.R.A family of group chain acceptance sampling plans based on truncated life test. PhD thesis, Universiti Utara Malaysia, 2018.

[11] Teh, M.A.P., Aziz, N. and Zain, Z. Group Chain Sampling Plans on Truncated Life Test for Log-Logistic Distributions.International Journal of Applied Engineering Research, Volume 11, Number 16, PP: 8971-8974. 2016.

[12] Teh, M.A.P., Aziz, N. and Zain, Z.Time Truncated Group Chain Sampling Plans for Rayleigh Distributions.Global Journal of Pure and Applied Mathematics, Volume 12, Number 4, PP: 3693-3699. 2016.

[13] Teh, M.A.P., Aziz, N. and Zain, Z. Group Chain Sampling Plans on Truncated Life Test for Inverse Rayleigh Distributions.Research Journal of Applied Sciences, Volume11, Issue 11, PP: 1432-1435. 2016.

[14] Teh, M.A.P., Aziz, N. and Zain, Z.Group Chain Sampling Plans Based on Truncated Life Test for Exponential Distributions.International Journal of Pure and Applied Mathematics, Volume 119, Number 3, PP: 491-500. 2018.

[15] Teh, M.A.P., Aziz, N. and Zain, Z.Constructing Group Chain Acceptance Sampling Plans (GChSP) for Gamma Distributions.International Journal of Innovative Technology and Exploring Engineering (IJITEE), Volume 8, Issue-5S. 2019.

[16] Mughal, A.R., Zain, Z. and Aziz, N. New Two-Sided Complete Group Chain Sampling Plan for Pareto Distribution of the 2nd Kind.International Journal of Applied Engineering Research, Volume 10, Number 12, PP: 31855 - 318860. 2015.

[17] Farouk, M., Aziz, N. and Zain, Z. "The New Two-Sided Group Chain Sampling Plan for Pareto Distribution of the 2nd Kind." International Journal of Innovative Technology and Exploring Engineering (IJITEE), Volume 8, Issue 5S. 2019.

[18] Ramaswamy, A. R. S., \& Sutharani, R. Designing double acceptance sampling plans based on truncated life tests inRayleigh distribution using minimum angle method. American Journal of Mathematics and Statistics, Volume 3, Issue 4, PP: 227-236. 2013. 